CARDIOVASCULAR MEDICINE

\title{
Beneficial effects of fluvastatin following percutaneous coronary intervention in patients with unstable and stable angina: results from the Lescol intervention prevention study (LIPS)
}

\author{
C H Lee, P de Feyter, P W Serruys, F Saia, P A Lemos, D Goedhart, P R Soares, V A W M Umans, \\ $M$ Ciccone, M Cortellaro
}

Heart 2004;90:1156-1161. doi: 10.1136/hrt.2003.027284

See end of article for authors' affiliations

\section{Correspondence to:} Dr Chi Hang Lee, Department of Cardiology, Thoraxcentre, Room Z120, University Hospital Diikzigt, Dr Molewaterplein 40 Rotterdam 3015 GD Netherlands; leerch@hotmail.com

Accepted 28 November 2003

\begin{abstract}
Aims: To investigate the effect on risk of major adverse cardiac events (MACE) of lipid lowering treatment with fluvastatin $80 \mathrm{mg} /$ day after a first percutaneous coronary intervention in patients with stable and unstable angina.

Method and results: This prespecified subgroup analysis of the LIPS (Lescol intervention prevention study) analysed 1658 patients with documented diagnosis; 824 had unstable angina (417 randomly assigned to fluvastatin, 407 to placebo) and 834 had stable angina (including silent ischaemia; fluvastatin, 418; placebo, 416). Median follow up was 3.9 years. There was no significant effect of anginal status on long term risk of MACE. Fluvastatin treatment reduced the risk of MACE by $28 \%$ compared with placebo ( $p=0.03$ ) among patients with unstable angina, with no difference between patients with stable and patients with unstable angina (relative risk 1.07, 95\% confidence interval 0.87 to $1.30, p=0.53$ ). Fluvastatin reduced coronary atherosclerotic events (MACE excluding restenosis) by $36 \%$ ( $p=0.006$ ) among patients with unstable angina and $31 \%(p=0.02)$ among patients with stable angina. Fluvastatin caused similar reductions in total cholesterol and low density lipoprotein cholesterol concentrations in both patient groups.

Conclusion: Treatment with fluvastatin $80 \mathrm{mg} /$ day produced significant reductions in MACE and coronary atherosclerotic events after percutaneous coronary intervention in patients with average cholesterol concentrations. The beneficial effects of fluvastatin are observed in patients with unstable or stable angina alike.
\end{abstract}

$\mathrm{R}$ ecent evidence suggests that coronary artery disease is a systemic disorder. ${ }^{12}$ Although percutaneous coronary intervention (PCI) effectively improves symptoms by restoring coronary perfusion, the underlying systemic inflammatory and prothrombotic substrates are not attenuated and so life long medication is necessary after revascularisation. In particular, lipid lowering treatment with 3-hydroxy-3methylglutaryl coenzyme A reductase inhibitors (statins) has been proved to improve survival in patients with coronary artery disease..$^{3-6}$ The underlying mechanisms for the beneficial effects of statins in patients with coronary artery disease are not fully understood but are likely to involve reductions in lipid concentrations, improvement in endothelial function, $^{78}$ anti-inflammatory action, ${ }^{9-12}$ or antithrombotic actions, ${ }^{11-13}$ or a combination of these effects. ${ }^{14}{ }^{15}$

The recent LIPS (Lescol intervention prevention study) showed that early initiation of lipid lowering treatment with fluvastatin at hospital discharge significantly reduces the incidence of major adverse cardiac events (MACE) among patients after PCI with average cholesterol concentrations. ${ }^{16}$ Fluvastatin treatment was well tolerated and associated with no significant side effects. In the present study, patients were classified at entry as having either unstable angina or stable angina, conditions that exhibit major differences in pathophysiology, ${ }^{17-19}$ prognosis, ${ }^{20}$ and response to treatment. ${ }^{21}$ In contrast to stable angina, which is caused by a fixed stenotic coronary lesion that impairs myocardial perfusion, unstable angina is usually caused by the rupture or erosion of an atherosclerotic plaque, leading to a reaction cascade that results in a thrombotic milieu. ${ }^{22}{ }^{23}$ There is relatively little information regarding the effect of statin treatment in patients with unstable angina; hence, this study provides important insight into the potential benefits of statins in this patient group.

The objective of the present study was thus to investigate the effects of fluvastatin on the incidence of long term adverse events among patients with unstable angina or stable angina enrolled in LIPS.

\section{METHODS}

\section{Patients}

Patients were recruited into LIPS from 57 centres in 10 countries between April 1996 and October 1998. The study population was composed of 1677 patients (1406 men and 271 women, age 18-80 years). All patients had successfully undergone a first PCI (index procedure) in the native coronary arteries. Patients qualifying for enrolment in LIPS had diagnosed unstable angina (according to the Braunwald classification), stable angina (according to the Canadian Cardiovascular Society classification), or silent ischaemia.

Patients were eligible for enrolment in the study if they had a total cholesterol concentration of 3.5-7.0 mmol/1 (135$270 \mathrm{mg} / \mathrm{dl}$ ) with fasting triglyceride concentrations of less than $4.5 \mathrm{mmol} / \mathrm{l}(400 \mathrm{mg} / \mathrm{dl})$ before the index procedure.

Abbreviations: $\mathrm{Cl}$, confidence interval; LIPS, Lescol intervention prevention study; MACE, major adverse cardiac events; PCI, percutaneous coronary intervention; RR, relative risk 
Exclusion criteria were sustained systolic blood pressure $>180 \mathrm{~mm} \mathrm{Hg}$ and diastolic blood pressure $>100 \mathrm{~mm} \mathrm{Hg}$ despite drug treatment; left ventricular ejection fraction $<30 \%$; a history of previous PCI or CABG, severe valvar disease, idiopathic cardiomyopathy, or congenital heart disease; severe renal dysfunction (defined as serum creatinine concentration $>160 \mu \mathrm{mol} / \mathrm{l} \quad(1.8 \mathrm{mg} / \mathrm{dl}))$; obesity (defined as a body mass index $>35 \mathrm{~kg} / \mathrm{m}^{2}$ ); or the presence of malignant or other disease with a life expectancy of less than four years.

All patients provided informed written consent and the ethics committee at each participating centre approved the trial.

\section{Study design}

After inclusion, patients were randomly assigned to receive either fluvastatin $40 \mathrm{mg}$ twice daily (Lescol, Novartis Pharma AG, Basel, Switzerland) or matching placebo for a period of at least three years and no longer than four years. The study design of LIPS has been described in more detail elsewhere. ${ }^{24}$

\section{End points}

The primary end point was MACE, defined as cardiac death, non-fatal myocardial infarction, or repeat intervention procedure. Prespecified secondary end points were MACE excluding repeat intervention procedures occurring in the first six months for lesions treated at the index procedure (MACE without restenosis or coronary atherosclerotic events) and cardiac death/non-fatal myocardial infarction. Secondary end points also included treatment effects on measured lipid concentrations throughout the trial, as well as the safety and tolerability of fluvastatin. Details and results of the main trial have been provided elsewhere. ${ }^{16}$

Laboratory measures, including serum total cholesterol, low density lipoprotein cholesterol, high density lipoprotein cholesterol, and fasting triglyceride concentrations, were determined from fasting blood samples and assessed at a central laboratory (Analytico Medinet, Breda, the Netherlands). Laboratory values were measured at baseline, at a clinical visit six weeks after discharge, and at six month intervals thereafter until the conclusion of the study. Study personnel and patients were not informed of the lipid results.

\section{Statistical analysis}

All analyses were carried out on an intention to treat basis. Continuous variables are expressed as mean (SD) and were compared by Student's unpaired $t$ test. Wilcoxon scores were used for categorical variables with an ordinal scale. Discrete variables are expressed as counts and percentages and were compared in terms of relative risks (RR) (for unstable angina compared with stable angina) with 95\% confidence interval (CI). All statistical tests were two tailed. Event-free survival distribution was estimated according to the Kaplan-Meier method. MACE-free survival time was tested with the log rank test. Patients lost to follow up were considered at risk until the date of last contact, at which point they were censored. The Cox proportional hazards model and the Cochran-Mantel-Haenszel test were used to assess risk reduction and to compare the incidences of the primary and secondary clinical end points, respectively. The treatment by anginal status interaction was calculated in a multivariate approach with treatment, anginal stability, and an interaction factor specifying the simultaneous presence or absence of both previous factors in the model. This enabled us to calculate the fluvastatin effect in patients with stable angina separate from the same effect in patients with unstable angina, as well as to calculate the anginal status effect in the patients given placebo and those given fluvastatin.
The lipid profiles were analysed in an analysis of covariance model incorporating the baseline (at visit l) as covariate, adding the factors treatment, visit number (visits $>1$ ), and subgroup with all possible interaction terms.

\section{RESULTS}

\section{Patient characteristics}

Of the 1677 patients enrolled in LIPS, data regarding qualifying diagnosis were complete for 1658 (98.9\%) patients. These patients were classed as having either unstable angina (total, 824; fluvastatin, 417; placebo, 407) or stable angina (total, 834; fluvastatin, 418; placebo, 416). Patients with silent ischaemia were included in the stable angina group.

Table 1 shows baseline characteristics (demographic and angiographic). There were no notable differences in the baseline and procedural characteristics between the groups. The left anterior descending artery was the affected vessel in a larger proportion of patients with unstable angina than in the stable angina group. The unstable angina group also had a higher incidence of American Heart Association classification type B2 lesions and stent implantation. In contrast, patients with diagnosed stable angina had a higher incidence of American Heart Association classification type $\mathrm{C}$ lesions and balloon angioplasty. In the unstable angina group, patients randomly assigned to fluvastatin had a higher incidence of diabetes mellitus and a lower incidence of previous stroke than did patients randomly assigned to placebo. Overall, patients randomly assigned to fluvastatin or placebo in the stable angina group were well matched.

The median time between index PCI and randomisation was two days in both groups (range 0-22 days in the unstable angina group and 0-21 days in the stable angina group). The median time from index PCI to initiation of study medication was also two days. The median follow up was 3.9 years in both groups.

Up to the time of the first MACE or completion of follow up among patients without MACE, 17.6\% (unstable angina group) and $17.5 \%$ (stable angina group) of patients were taking the study treatment regimen less than $80 \%$ of the time and were not taking other lipid lowering drugs. It is worth noting that $16.9 \%$ of patients in the unstable angina group and $17.6 \%$ of patients in the stable angina group were taking other lipid lowering drugs (generally other statins).

The proportion of patients taking other cardiovascular drugs during the course of the study was similar between the groups. Concurrent treatments included aspirin, $\beta$ blockers, calcium antagonists, nitrates, angiotensin converting enzyme inhibitors, and diuretics.

\section{Long term risk of unstable versus stable angina after $\mathrm{PCl}$}

Among patients randomly assigned to placebo, the overall incidence of MACE was similar in patients with unstable angina $(27.3 \%)$ and patients with stable angina (26.2\%) (RR $0.88,95 \%$ CI 0.66 to $1.17, p=0.37$ ). The overall incidence of MACE in the two angina categories was also similar in patients randomly assigned to receive fluvastatin (unstable versus stable angina $20.9 \%$ v $22.3 \%$, RR $1.0,95 \%$ CI 0.73 to $1.37, \mathrm{p}=1.0)$. Overall, there was no significant effect of anginal status on long term risk of MACE (RR 0.94, 95\% CI 0.75 to $1.17, \mathrm{p}=0.56$ ). Similarly, there was no significant difference in risk between patients with unstable angina and those with stable angina in other end points, including cardiac death/non-fatal MI or coronary atherosclerotic events (MACE without restenosis). 
Table 1 Patient demographics and characteristics at baseline

\begin{tabular}{|c|c|c|c|c|}
\hline & \multicolumn{2}{|c|}{ Unstable angina } & \multicolumn{2}{|l|}{ Stable angina } \\
\hline & $\begin{array}{l}\text { Fluvastatin } \\
(n=417)\end{array}$ & $\begin{array}{l}\text { Placebo } \\
(n=407)\end{array}$ & $\begin{array}{l}\text { Fluvastatin } \\
(n=418)\end{array}$ & $\begin{array}{l}\text { Placebo } \\
(n=416)\end{array}$ \\
\hline Age (years) & $60.7(10.2)$ & $60.2(9.9)$ & $59.5(10.0)$ & $59.8(9.8)$ \\
\hline Men & $344(82.5 \%)$ & $336(82.6 \%)$ & $360(86.1 \%)$ & $350(84.1 \%)$ \\
\hline BMI $\left(\mathrm{kg} / \mathrm{m}^{2}\right)$ & 26.9 & 26.3 & 26.5 & 26.5 \\
\hline \multicolumn{5}{|l|}{ Risk factors } \\
\hline Smoking (previous and current) & $303(72.7 \%)$ & $297(73.0 \%)$ & $293(70.1 \%)$ & $288(69.2 \%)$ \\
\hline Diabetes & $65(15.6 \%)$ & $34(8.4 \%)$ & $55(13.2 \%)$ & $48(11.5 \%)$ \\
\hline Hypertension & $157(37.6 \%)$ & $158(38.8 \%)$ & $169(40.4 \%)$ & $157(37.7 \%)$ \\
\hline Family history of IHD & $113(27.4 \%)$ & 119 (29.3\%) & $125(30.0 \%)$ & $131(31.7 \%)$ \\
\hline Previous MI & $184(44.1 \%)$ & $172(42.3 \%)$ & $179(42.8 \%)$ & $192(46.2 \%)$ \\
\hline Previous stroke & $10(2.4 \%)$ & $21(5.2 \%)$ & $7(1.7 \%)$ & $6(1.4 \%)$ \\
\hline Multivessel disease & $148(35.5 \%)$ & $138(339 \%)$ & $170(40.7 \%)$ & $149(35.8 \%)$ \\
\hline \multicolumn{5}{|l|}{ Braunwald classification } \\
\hline IB & $53(12.7 \%)$ & $49(12.0 \%)$ & NA & NA \\
\hline IIB & $186(44.6 \%)$ & $195(47.9 \%)$ & NA & NA \\
\hline IIIB & $82(19.7 \%)$ & $79(19.4 \%)$ & NA & NA \\
\hline IC & $11(2.6 \%)$ & $10(2.5 \%)$ & NA & NA \\
\hline$\| \mathrm{C}$ & 49 (11.8\%) & $34(8.4 \%)$ & NA & NA \\
\hline IIIC & $36(8.6 \%)$ & $40(9.8 \%)$ & NA & NA \\
\hline \multicolumn{5}{|l|}{ CCS classification (\%) } \\
\hline I & NA & NA & $44(10.5 \%)$ & $45(10.8 \%)$ \\
\hline$\|$ & NA & NA & $180(43.1 \%)$ & $161(38.7 \%)$ \\
\hline III & NA & NA & $99(23.7 \%)$ & $101(24.3 \%)$ \\
\hline IV & NA & NA & $23(5.5 \%)$ & $18(4.3 \%)$ \\
\hline Silent ischaemia & NA & NA & $72(17.2 \%)$ & $91(21.9 \%)$ \\
\hline \multicolumn{5}{|l|}{ Baseline lipid concentration (mmol/) } \\
\hline Total cholesterol & $5.17(0.81)$ & $5.16(0.84)$ & $5.19(0.80)$ & $5.17(0.87)$ \\
\hline LDL cholesterol & $3.43(0.75)$ & $3.42(0.79)$ & $3.40(0.76)$ & $3.42(0.80)$ \\
\hline HDL cholesterol & $0.95(0.28)$ & $0.95(0.26)$ & $1.00(0.34)$ & $0.98(0.33)$ \\
\hline Triglycerides & $1.75(0.68)$ & $1.75(0.71)$ & $1.75(0.87)$ & $1.71(0.73)$ \\
\hline Systolic BP (mm Hg) & 128 & 127 & 129 & 130 \\
\hline Diastolic BP (mm Hg) & 74 & 75 & 76 & 76 \\
\hline Ejection fraction (\%) & 62.0 & 62.9 & 62.7 & 60.8 \\
\hline \multicolumn{5}{|l|}{ Lesion type (AHA class) } \\
\hline A & $20.3 \%$ & $18.6 \%$ & $19.4 \%$ & $20.1 \%$ \\
\hline B1 & $34.1 \%$ & $35.6 \%$ & $35.3 \%$ & $35.9 \%$ \\
\hline B2 & $36.5 \%$ & $36.2 \%$ & $30.5 \%$ & $29.6 \%$ \\
\hline C & $9.1 \%$ & $9.6 \%$ & $14.8 \%$ & $14.4 \%$ \\
\hline \multicolumn{5}{|l|}{ Type of $\mathrm{PCl}^{*}$} \\
\hline Balloon only & $37.6 \%$ & $38.7 \%$ & $46.0 \%$ & $44.8 \%$ \\
\hline Stent & $61.7 \%$ & $58.8 \%$ & $50.9 \%$ & $52.3 \%$ \\
\hline Others & $3.4 \%$ & $4.5 \%$ & $4.4 \%$ & $5.1 \%$ \\
\hline \multicolumn{5}{|c|}{$\begin{array}{l}\text { *Percutaneous coronary intervention (PCI) categories are not mutually exclusive; hence, percentage values may no } \\
\text { total 100\%. } \\
\text { AHA, American Heart Association; BMI, body mass index; BP, blood pressure; CCS, Canadian Cardiovascular } \\
\text { Society; HDL, high density lipoprotein; IHD, ischaemic heart disease; LDL, low density lipoprotein; MI, myocardic } \\
\text { infarction; NA, not applicable. }\end{array}$} \\
\hline
\end{tabular}

\section{Effect of fluvastatin in unstable and stable angina after $\mathrm{PCl}$}

Table 2 shows the effect of fluvastatin on the time to first end point. In patients with unstable angina, fluvastatin treatment produced a significant risk reduction for MACE of $28 \%$ $(\mathrm{p}=0.03)$. The treatment-status interaction analysis showed that the effect of fluvastatin treatment did not differ significantly between patients with stable angina and patients with unstable angina (RR 1.07, 95\% CI 0.87 to $1.30, \mathrm{p}=0.53)$. The Kaplan-Meier curves for fluvastatin and placebo groups started to separate at around 1.5 years and the benefits of fluvastatin treatment appeared to increase with time (fig 1).

Table 2 shows the effects of fluvastatin on other prespecified cardiovascular outcomes and fig l compares these outcomes. In patients with unstable angina, fluvastatin treatment significantly lowered the risk of coronary atherosclerotic events (incidence $23.1 \%$ with placebo $v 16.3 \%$, $\mathrm{RR}=0.64,95 \%$ CI 0.46 to $0.88 ; \mathrm{p}=0.006$ ) but not the risk of cardiac death/non-fatal myocardial infarction (incidence

Table 2 Effects of fluvastatin on prespecified cardiovascular end points

\begin{tabular}{|c|c|c|c|c|c|c|c|c|}
\hline \multirow[b]{2}{*}{ End point } & \multicolumn{4}{|c|}{ Unstable angina } & \multicolumn{4}{|c|}{ Stable angina } \\
\hline & $\begin{array}{l}\text { Fluvastatin } \\
(n=417)\end{array}$ & $\begin{array}{l}\text { Placebo } \\
(n=407)\end{array}$ & $\operatorname{RR}(95 \% \mathrm{Cl})$ & p Value & $\begin{array}{l}\text { Fluvastatin } \\
\text { ( } n=418)\end{array}$ & $\begin{array}{l}\text { Placebo } \\
(n=416)\end{array}$ & $\operatorname{RR}(95 \% \mathrm{CI})$ & p Value \\
\hline $\begin{array}{l}\text { MACE without } \\
\text { restenosis }\end{array}$ & $68(16.3 \%)$ & $94(23.1 \%)$ & $0.64(0.46$ to 0.88$)$ & 0.006 & $66(15.8 \%)$ & $92(22.1 \%)$ & $0.69(0.50$ to 0.95$)$ & 0.02 \\
\hline $\begin{array}{l}\text { Cardiac death/non- } \\
\text { fatal Ml }\end{array}$ & $22(5.3 \%)$ & $35(8.6 \%)$ & $0.60(0.34$ to 1.03$)$ & 0.06 & $20(4.8 \%)$ & $24(5.8 \%)$ & $0.85(0.46$ to 1.55$)$ & 0.59 \\
\hline Time to first MACE & NA & NA & $0.72(0.47$ to 0.90$)$ & 0.03 & NA & NA & 0.80 (0.60 to 1.07$)$ & 0.13 \\
\hline
\end{tabular}


$8.6 \%$ with placebo $v 5.3 \%$, RR $=0.60,95 \%$ CI 0.34 to 1.05 ; $\mathrm{p}=0.06$ ). Fluvastatin also significantly decreased the risk of coronary atherosclerotic events in patients with stable angina (incidence $22.1 \%$ with placebo $v 15.8 \%, \mathrm{RR}=0.69,95 \% \mathrm{CI}$ 0.50 to $0.95 ; p=0.02$ ), although the reduction in cardiac death/non-fatal myocardial infarction was not significant (incidence $5.8 \%$ with placebo $v 4.8 \%, \mathrm{RR}=0.85,95 \%$ CI 0.46 to $1.55 ; \mathrm{p}=0.59$ ).

The proportion of patients with unstable angina with no MACE did not vary significantly according to Braunwald classification in either the fluvastatin (class I, 75\%; class II, $80 \%$; class III, $80 \%$ ) or the placebo group (class I, $81 \%$; class II, 73\%; class III, 68\%).

\section{Changes in lipid concentrations}

Baseline lipid concentrations were similar in the unstable angina and stable angina groups, as well as in the fluvastatin and placebo arms within each group (table 1). Figure 2 and table 3 show the changes in lipid concentrations with fluvastatin analysed on an intention to treat basis. Fluvastatin produced a significant reduction in total and low density lipoprotein cholesterol concentrations in both the unstable and stable angina groups, with comparable efficacy in the two groups. Reductions in lipid concentrations were first observed at visit 2 ( six weeks after discharge) and were maintained throughout the study period. Although high density lipoprotein cholesterol concentrations increased above baseline concentrations in both the unstable and stable angina groups, similar increases were observed in patients randomly assigned to placebo; hence, there was no net benefit in favour of fluvastatin. Similarly, no significant changes in triglyceride concentrations attributable to fluvastatin were observed in either group.

\section{Safety and tolerability}

Full safety data have been reported previously. ${ }^{16}$ No significant adverse events were observed with fluvastatin.

\section{DISCUSSION}

LIPS was the first prospective study of patients with average lipid concentrations after successful PCI, with a significant reduction of $22 \%$ in fatal or non-fatal MACE as a result of early statin treatment with fluvastatin $80 \mathrm{mg} /$ day. These results support the use of early lipid lowering treatment with fluvastatin for patients after PCI regardless of baseline lipid concentration.

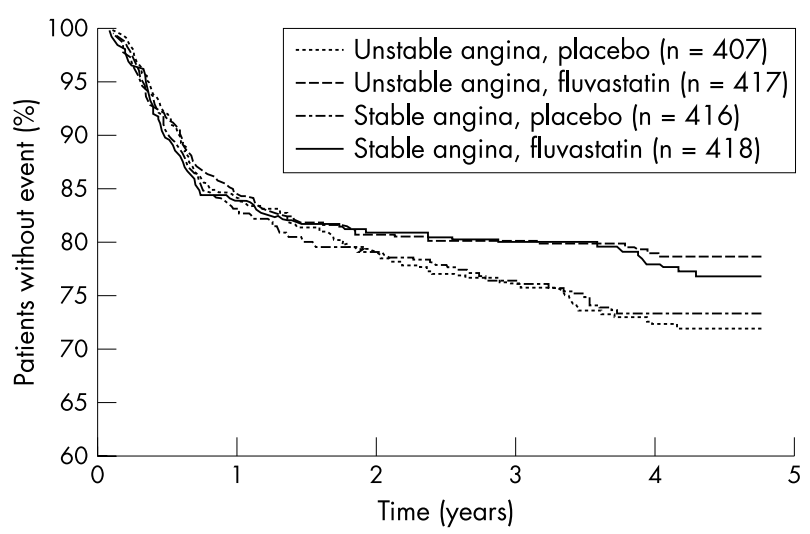

Figure 1 Kaplan-Meier curves showing survival time free of adverse coronary atherosclerotic events (cardiac death, non-fatal myocardial infarction, and all reinterventions not caused by coronary restenosis) in patients with stable or unstable angina randomly assigned to receive either fluvastatin $80 \mathrm{mg} /$ day or placebo.
Most previous studies investigating the long term effects of statin have focused on patients after an infarction or with stable angina. ${ }^{3-6}$ Information regarding the effects of statin in patients with unstable angina, particularly after PCI, is scarce. LIPS therefore offered the opportunity to investigate the effect of fluvastatin in patients with unstable angina who had successfully undergone PCI, a group that made up approximately half of the LIPS population.

The results of the present study show that patients classed as having both unstable and stable angina in LIPS had an
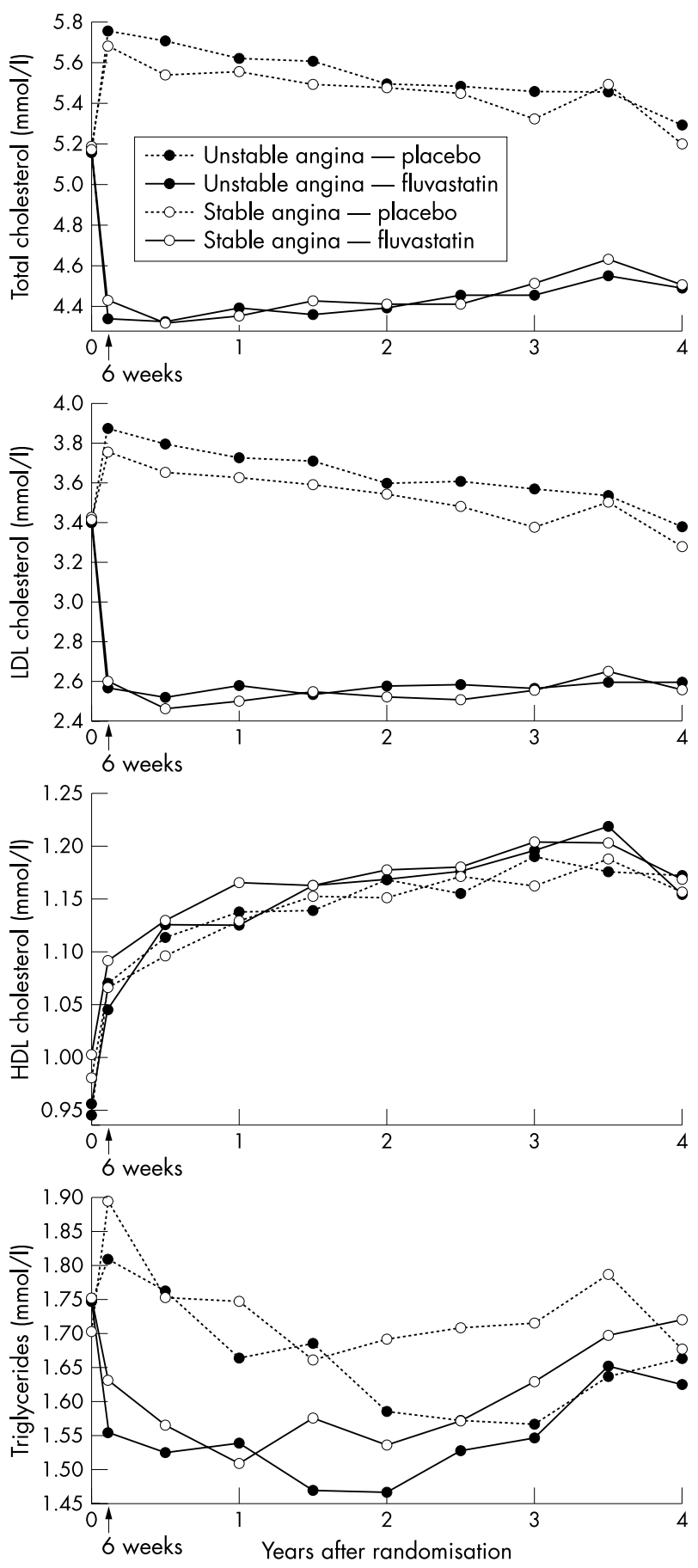

Figure 2 Mean change in lipid concentrations throughout follow up among patients with stable or unstable angina randomly assigned to receive either fluvastatin $80 \mathrm{mg} /$ day or placebo. (A) Total cholesterol; (B) low density lipoprotein (LDL) cholesterol; (C) high density lipoprotein (HDL) cholesterol; (D) triglyceride concentrations. 
Table 3 Differences in blood lipid concentrations between fluvastatin and placebo treatment groups at the end of the study

\begin{tabular}{|c|c|c|c|c|c|c|c|c|}
\hline & \multicolumn{4}{|c|}{ Unstable angina } & \multicolumn{4}{|l|}{ Stable angina } \\
\hline & \multicolumn{2}{|c|}{ Fluvastatin $(n=417)$} & \multicolumn{2}{|c|}{ Placebo $(n=407)$} & \multicolumn{2}{|c|}{ Fluvastatin ( $n=418$ ) } & \multicolumn{2}{|c|}{ Placebo $(n=416)$} \\
\hline & $\begin{array}{l}\text { Concentration } \\
\text { (mmol/) }\end{array}$ & $\begin{array}{l}\text { Change from } \\
\text { baseline }\end{array}$ & $\begin{array}{l}\text { Concentration } \\
\text { (mmol/l) }\end{array}$ & $\begin{array}{l}\text { Change from } \\
\text { baseline }\end{array}$ & $\begin{array}{l}\text { Concentration } \\
\text { (mmol/l) }\end{array}$ & $\begin{array}{l}\text { Change from } \\
\text { baseline }\end{array}$ & $\begin{array}{l}\text { Concentration } \\
\text { (mmol/l) }\end{array}$ & $\begin{array}{l}\text { Change from } \\
\text { baseline }\end{array}$ \\
\hline $\begin{array}{l}\text { Total cholesterol } \\
\text { LDL cholesterol } \\
\text { HDL cholesterol } \\
\text { Triglycerides }\end{array}$ & $\begin{array}{r}-0.65 \\
-0.79 \\
0.21 \\
-0.15\end{array}$ & $\begin{array}{r}-12.6 \% \\
-23.0 \% \\
22.1 \% \\
-8.6 \%\end{array}$ & $\begin{array}{r}0.10 \\
-0.04 \\
0.22 \\
-0.15\end{array}$ & $\begin{array}{r}1.9 \% \\
-1.2 \% \\
23.2 \% \\
-8.6 \% \\
\end{array}$ & $\begin{array}{r}-0.62 \\
-0.76 \\
0.17 \\
-0.11\end{array}$ & $\begin{array}{r}-11.9 \% \\
-22.4 \% \\
17.0 \% \\
-6.3 \%\end{array}$ & $\begin{array}{r}0.03 \\
-0.09 \\
0.21 \\
-0.17\end{array}$ & $\begin{array}{r}0.6 \% \\
-2.6 \% \\
21.4 \% \\
-9.9 \%\end{array}$ \\
\hline
\end{tabular}

impaired long term prognosis, with up to one quarter to one third of patients experiencing one or more MACE within four years of PCI. These findings emphasise the importance of additional treatment after successful revascularisation. Importantly, fluvastatin treatment was of clear benefit both for patients with stable angina and for patients with unstable angina and was associated with clinically relevant reductions in the incidence of coronary atherosclerotic events in both patient groups. The benefits of fluvastatin treatment in reducing the incidence of MACE and prolonging the time to first MACE were significant in patients with unstable angina. A treatment-status interaction analysis showed no significant difference in the effects of fluvastatin between patients with unstable angina and patients with stable angina.

There was also no significant difference in outcome between patients with stable angina and those with unstable angina in the placebo group. This is somewhat surprising but may be a result of the successful PCI that took place before randomisation, which not only treats the obstructive lesion but also stabilises any initially unstable culprit plaque.

Previous studies have shown that, after successful coronary angioplasty, patients with unstable angina have a higher event rate than do patients with stable angina. This has generally been attributed to a higher repeat revascularisation rate. ${ }^{21}$ In contrast, LIPS showed that unstable and stable angina had comparable long term outcomes after successful revascularisation. There are several possible reasons for the difference. Firstly, this difference may reflect the more widespread use of coronary stent, a technique that has been proved to reduce restenosis ${ }^{25}$ in LIPS. Secondly, the inherited bias of recruiting solely patients with unstable angina who have undergone successful angioplasty could have effaced the risk imposed by the disease entity. Thirdly, the administration of new adjunctive medications such as glycoprotein IIb/IIIa inhibitors for unstable angina may also have contributed to lowering the risk of this patient group.

For patients with unstable coronary syndrome, early initiation of statin before hospital discharge has been independently associated with a reduction in MACE in the short term, ${ }^{26-28}$ as well as over long term follow up. ${ }^{29}$ However, successful revascularisation was not an inclusion criterion in these studies. It has also been reported that early initiation of statin for patients with unstable angina undergoing stent implantation is associated with an improvement in six month outcomes. $^{30}$ Long term event rates, however, were not reported. Given the positive effects of fluvastatin on long term outcomes in both patients with unstable angina and those with stable angina in our analysis, extrapolation of previous findings to all patients with coronary artery disease who have undergone a first successful PCI seems reasonable.

The beneficial effects of statin among patients with unstable angina may be attributed to its effect on vulnerable plaques, as vulnerable plaque rupture is the major triggering event for unstable coronary disease. Experimental data suggest that statin, in addition to its lipid lowering effects, may stabilise vulnerable plaques by converting lipid rich plaques (which are at high risk of rupture) into more stable fibrotic plaques. ${ }^{31}$

\section{Study limitations}

Because the number of patients with silent ischaemia was small, this group was included in the stable angina group for analysis. Patients with previous PCI or coronary bypass surgery were excluded; hence, the conclusions of the present study cannot be extrapolated to these patients. As this study is an analysis of a subgroup, albeit prespecified, it suffers from inherent limitations, such as the lack of sufficient power, because of the limited number of patients in each subgroup.

\section{Conclusions}

The results of the present study provide evidence for the long term benefits of fluvastatin treatment initiated at hospital discharge for all patients with angina after successful PCI. It is worth noting that evidence from previous studies has shown that early initiation of lipid lowering treatment before hospital discharge also improves compliance. ${ }^{32}$ On the basis of these findings, we suggest that early lipid lowering treatment should be initiated for all patients after PCI, regardless of baseline lipid concentrations and clinical presentation.

\section{ACKNOWLEDGEMENTS}

This study was supported by a grant from Novartis Pharma AG. Novartis provided the fluvastatin and matched placebo used in the present study.

\section{Authors' affiliations}

C H Lee, P de Feyter, P W Serruys, F Saia, P A Lemos, Erasmus Medical Centre, Thoraxcentre, Rotterdam, the Netherlands

D Goedhart, Cardialysis BV, Rotterdam, the Netherlands

P R Soares, Heart Institute (InCor) of Sao Paulo University Medical School, Sao Paulo, Brazil

V A W M Umans, Medical Centre Alkmaar, the Netherlands

M Ciccone, Dipartimento di Metodologia Clinica e Tecnologie MedicoChirurgiche, University of Bari, Bari, Italy

M Cortellaro, Istituto Policlinico S Donato, San Donato Milanese, Italy

\section{REFERENCES}

1 Drouet $\mathrm{L}$. Atherothrombosis as a systemic disease. Cerebrovasc Dis 2002;13(suppl 1):1-6.

2 Falk E. Multiple culprits in acute coronary syndromes: systemic disease calling for systemic treatment. Ital Heart J 2000;1:835-8.

3 Sacks FM, Pfeffer MA, Moye LA, for the Cholesterol and Recurrent Events Trial Investigators, et al. The effect of pravastatin on coronary events after myocardial infarction in patients with average cholesterol levels. N Engl J Med 1996;335:1001-9

4 Anon. Prevention of cardiovascular events and death with pravastatin in patients with coronary heart disease and a broad range of initial cholesterol levels. The long-term intervention with pravastatin in ischaemic disease (LIPID) study group. N Engl J Med 1998;339:1349-57.

5 Anon. Long-term effectiveness and safety of pravastatin in 9014 patients with coronary heart disease and average cholesterol concentrations: the LIPID trial 
follow-up. The LIPID study group (long-term intervention with pravastatin in ischaemic disease). Lancet 2002;359:1379-87.

6 Herrington DM, Vittinghoff E, Lin F, et al. Statin therapy, cardiovascular events, and total mortality in the heart and estrogen/progestin replacement study (HERS). HERS study group. Circulation 2002;105:2962-7.

7 Dupuis J, Tardif JC, Cernacek P, et al. Cholesterol reduction rapidly improves endothelial function after acute coronary syndromes. The RECIFE (reduction of cholesterol in ischemia and function of the endothelium) trial. Circulation 1999;99:3227-33.

8 Masumoto A, Hirooka Y, Hironaga K, et al. Effect of pravastatin on endothelial function in patients with coronary artery disease (cholesterolindependent effect of pravastatin). Am J Cardiol 2001;88:1291-4.

9 Ridker PM, Rifai N, Pfeffer MA, et al. Long-term effects of pravastatin on plasma concentration of $\mathrm{C}$-reactive protein. The cholesterol and recurrent events (CARE) investigators. Circulation 1999;100:230-5.

10 Martinez-Gonzalez J, Alfon J, Berrozpe M, et al. HMG-CoA reductase inhibitors reduce vascular monocyte chemotactic protein-1 expression in early lesions from hypercholesterolemic swine independently of their effect on plasma cholesterol levels. Atherosclerosis 2001;159:27-33.

$11 \mathrm{Ni} \mathrm{W}$, Egashira K, Kataoka C, et al. Antiinflammatory and antiarteriosclerotic actions of HMG-CoA reductase inhibitors in a rat model of chronic inhibition of nitric oxide synthesis. Circ Res 2001;89:415-21.

12 Undas A, Brozek J, Musial J. Anti-inflammatory and antithrombotic effects of statins in the management of coronary artery disease. Clin Lab 2002;48:287-96.

13 Lacoste L, Lam JY, Hung J, et al. Hyperlipidemia and coronary disease: correction of the increased thrombogenic potential with cholesterol reduction. Circulation 1995:92:3172-7.

14 Rauch U, Osende Jl, Chesebro JH, et al. Statins and cardiovascular diseases: the multiple effects of lipid-lowering therapy by statins. Atherosclerosis 2000;153:181-9.

15 Koh KK. Effects of statins on vascular wall: vasomotor function, inflammation, and plaque stability. Cardiovasc Res 2000;47:648-57.

16 Serruys PW, de Feyter P, Macaya C, et al. Fluvastatin for prevention of cardiac events following successful first percutaneous coronary intervention: a randomized controlled trial. Lescol intervention prevention study (LIPS) investigators. JAMA 2002;287:3215-22.

17 Sullivan E, Kearney M, Isner JM, et al. Pathology of unstable angina: analysis of biopsies obtained by directional coronary atherectomy. J Thromb Thrombolysis 1994;1:63-71.

18 Walczak E, Krus S, Fiejka E, et al. Light and electron microscopic picture of atherosclerotic plaque in stable and unstable angina. Pol J Pathol 1999:50:87-92.

19 Hoffmeister HM, Ehlers R, Buttcher E, et al. Comparison of C-reactive protein and terminal complement complex in patients with unstable angina pectoris versus stable angina pectoris. Am J Cardiol 2002;89:909-12.
20 Fiotti N, Di Chiara A, Altamura N, et al. Coagulation indicators in chronic stable effort angina and unstable angina: relationship with acute phase reactants and clinical outcome. Blood Coagul Fibrinolysis 2002; 13:247-55.

21 Przewlocki T, Pieniazek P, Tracz W, et al. Long-term outcome in patients with unstable angina treated by coronary balloon angioplasty. Int J Cardiol 2001;77:13-24.

22 Davies MJ, Thomas AC, Knapman PA, et al. Intramyocardial platelet aggregation in patients with unstable angina suffering sudden ischemic cardiac death. Circulation 1986;73:418-27.

23 Falk E. Unstable angina with fatal outcome: dynamic coronary thrombosis leading to infarction and/or sudden death: autopsy evidence of recurrent mural thrombosis with peripheral embolization culminating in total vascular occlusion. Circulation 1985;71:699-708.

24 Serruys PW, De Feyter PJ, Benghozi R, et al. Lescol(R) intervention prevention study (LIPS): a double-blind, placebo-controlled, randomized trial of the longterm effects of fluvastatin after successful transcatheter therapy in patients with coronary heart disease. Int J Cardiovasc Intervent 2001;4:165-72.

25 Serruys PW, de Jaegere P, Kiemeneij F, et al. A comparison of balloonexpandable-stent implantation with balloon angioplasty in patients with coronary artery disease. Benestent study group. N Engl J Med 1994;331:489-95.

26 Bybee KA, Wright RS, Williams BA, et al. Effect of concomitant or very early statin administration on in-hospital mortality and reinfarction in patients with acute myocardial infarction. Am J Cardiol 2001;87:771-4, A7.

27 Aronow HD, Topol EJ, Roe MT, et al. Effect of lipid-lowering therapy on early mortality after acute coronary syndromes: an observational study. Lancet 2001;357:1063-8.

28 Schwartz GG, Olsson AG, Ezekowitz MD, et al. Effects of atorvastatin on early recurrent ischemic events in acute coronary syndromes: the MIRACL study: a randomized controlled trial. Myocardial ischemia reduction with aggressive cholesterol lowering (MIRACL) study investigators. JAMA 2001;285:1711-8.

29 Tonkin AM, Colquhoun D, Emberson J, et al. Of pravastatin in 3260 patients with unstable angina: results from the LIPID study. Lancet 2000;356:1871-5.

30 Walter DH, Fichtlscherer S, Britten MB, et al. Benefits of immediate initiation of statin therapy following successful coronary stent implantation in patients with stable and unstable angina pectoris and $Q$-wave acute myocardial infarction. Am J Cardiol 2002;89:1-6.

31 Shiomi M, Ito T, Hirouchi Y, et al. Fibromuscular cap composition is important for the stability of established atherosclerotic plaques in mature WHHL rabbits treated with statins. Atherosclerosis 2001;157:75-84.

32 Hunninghake DB. Postdischarge lipid management of coronary artery disease patients according to the new national cholesterol education program guidelines. Am J Cardiol 2001;88:37K-41K

\title{
FROM BMJ JOURNALS
}

\section{Systematic review of interventions to reduce delay in patients with suspected heart attack}

\author{
A Kainth, A Hewitt, J Pattenden, A Sowden, S Duffy, I Watt, D Thompson, R Lewin
}

Please visit the Heart website [www heartinl. com] for a link to the full text of this article.
Objectives: To evaluate the effectiveness of interventions aiming to reduce time from onset of signs and symptoms of an acute myocardial infarction (AMI) to seeking medical help/ arrival at hospital.

Methods: A systematic review was conducted. Fifteen electronic databases, the internet, and bibliographies of included studies were searched, and experts in the field of cardiac care were contacted. Randomised controlled trials (RCTs), controlled trials, and before and after studies conducted in any setting that assessed an intervention aimed at reducing time from onset of signs and symptoms of an AMI to seeking medical help and/or arrival in hospital were eligible for inclusion.

Results: Eleven media/public education intervention studies met the inclusion criteria. Five (one controlled and four before and after studies) reported the intervention to have a statistically positive effect on delay time and six (two RCTs and four before and after studies) reported no statistically significant effect. Three (one RCT and two before and after studies) of five studies evaluating the effect of the intervention on emergency department visits reported an increase in this outcome as a result of the intervention, and both studies (one RCT and one before and after study) examining calls made to emergency switchboards reported an increase in this outcome after the intervention.

Conclusions: There was little evidence that media/public education interventions reduced delay. There is some evidence that they may result in an increase in emergency switchboard calls and emergency department visits. Despite substantial expenditure of time and effort, methodological deficiencies of the studies mean that it is not possible to make definitive recommendations.

A Emergency Medicine Journal 2004;21:506-508. 